\title{
Student Engagement as Pathway for Deterritorialising Curriculum Internationalisation in Higher Education
}

\author{
Kehdinga G. Fomunyam \\ Institute of System Science, Durban University of Technology, South Africa
}

Received October 8, 2019; Revised March 24, 2020; Accepted March 28, 2020

Copyright $\bigcirc 2020$ by authors, all rights reserved. Authors agree that this article remains permanently open access under the terms of the Creative Commons Attribution License 4.0 International License

\begin{abstract}
This paper explores the concept of curriculum internationalisation in higher education. It recognises and articulates the fact that the curriculum internationalisation process needs to be deterritorialised and the best approach to this is ensuring student engagement. In discussing this in detail, the paper theorises student engagement and the different perspectives on and of engagement, discusses curriculum internationalisation and deterritorialisation. The paper then focuses on deterritorialising curriculum internationalisation through student engagement. The paper concludes with four key thoughts on curriculum internationalisation on the platform of student engagement in a deterritorialised context. The paper recommends that curriculum internationalisation should be contextual in nature. Also, deterritorialisation of the institution and the curriculum internationalisation process and the curriculum itself are key to successfully internationalising the curriculum and give students the best educational experience. Thirdly, for the curriculum internationalisation process to be successful, there is a need for a practical framework. And lastly, student engagement is critical in the internationalisation process and for the success of curriculum internationalisation itself.
\end{abstract}

Keywords Curriculum Internationalisation,
$\begin{aligned} & \text { Deterritorialisation, Student Engagement, Higher } \\ & \text { Education and Students }\end{aligned}$

\section{Introduction}

Student engagement in higher education has grown to mean different things for different higher education institutions and practitioners depending on the kind and quality of students they have as well as the social and cultural capital possessed by these students. Gunuc and Kuzu (2015) argue that in recent times there has been much interest in higher education literature and policy on the notion of student engagement and researchers fully agree on the meaning of the term making. They add that student engagement is considered by all higher education stake holders as an important prerequisite for improving student achievement and student experience but cannot agree on exactly what student engagement is. Axelson and Flick (2010) argue that student engagement has been understood as involving students in activities that are linked with high-quality learning or as participation in educationally effective practices, both inside and outside the classroom, which can or lead to a range of measurable outcomes. They conclude by defining student engagement as ensuring "students have a positive, fulfilling and work-related state of mind that is characterised by vigour, dedication and absorption and who views him or herself as belonging to, and an active participant in, his or her learning communities” (Baron \& Corbin, 2012, p. 763). This means that student engagement has to do with improving student experience as well as performance or the quality of graduates produced.

Axelson and Flick (2010, p. 41) in an attempt to clarify the term argue that there have been two opposing popular views of student engagement. On the one hand, student engagement is seen as "an accountability measure that provides a general index of students' involvement with their learning environments" and on the other it is seen "as a variable in educational research that is aimed at understanding, explaining, and predicting student behaviour in learning environments". The challenge with these views lies in its inability to consider aspects of engagement which cannot be measured and the potential of this emotional and psychological levels of engagement to contribute to overall student experience. Coates (2010), Kahu (2013) and Vuori (2014) add that student engagement can be summarily understood from four perspectives; the first sees student engagement as behaviour or how students and the institution interact. That is seen by the time and effort students devote to activities that are empirically linked to desired outcomes of what 
institutions do to induce students to participate in these activities. The second perspective sees student engagement as the student's psychosocial process, emphasizing the cognitive and affective dimensions of an individual. The third perspective sees student engagement as the socio-political context, by focusing on institutional culture and wider contextual issues. Those are the conditioning and enabling factors within the institution that makes for engagement. The fourth and final perspective sees student engagement as a process that has been designed by the institution and as an outcome that results from students' efforts, motivations and expectations. These four perspectives behavioural, psychological, socio-cultural and holistic perspective make student engagement a complicated subject. It is this complication that makes it difficult for students to be engaged in curriculum discourses.

With internationalisation increasingly gaining grounds across the nations of the earth and student mobility gaining ground, there has been increasing demands for internationalisation of the curriculum to improve the academic experience of students in the education world. Curriculum internationalisation is a complex process involving a complex mix of people and complex approaches. What direction should curriculum internationalisation take, how should curriculum be internationalised and who should internationalise it are current questions which the academic world is dabbling with. This paper argues for curriculum internationalisation by deterritorialising through these four perspectives of student engagement. To do this, the paper is divided into three parts curriculum internationalisation, deterritorialising and deterritorialising curriculum internationalisation through student engagement.

\section{Curriculum Internationalisation}

Curriculum internationalisation just like curriculum means different things to different scholars. Leask and Bridge (2013) argue that it is the combination of an international and intercultural perspective into curriculum content, teaching and learning and support services. This definition takes into account most aspects of curriculum being supported, content and delivery but fails to look at experience. Haigh (2002) adding to this argue that curriculum internationalisation is the process of designing a curriculum that meets the needs of an international student body. This means curriculum internationalisation is about meeting the curriculum needs of the increasingly international student body. For this to happen, the specificity of the student body needs to be taken into consideration to ensure that irrespective of their national, ethnic, cultural, social class, or gender identities the curriculum speaks to their needs. Haigh (2002, p. 51) adds that curriculum internationalisation "contains the belief that a university should grant an equal opportunity for success to every student that it enrolls and not prejudice the advancement of any individual by granting an innate competitive advantage to students from any particular social group or tradition”. It must therefore give every student a fair opportunity and chance to compete and this competetition needs to happen at a global and non-contextual scale, or practically contextualised that every individual feels at home. Curriculum internationalisation is therefore about a universal suffrage. A universal suffrage must therefore contain input or participation from most or all students within the institution. This becomes a challenge especially in higher education where institutions have tens of thousands of students. Getting input from all students and harnessing such inputs become a herculean task.

Leask (2015) provides a nine-point framework for the internationalisation of the curriculum. Firstly, she points out that knowledge in and across disciplines is critical for the internationalisation of the curriculum and is at the centre of the framework. Disciplines constitute the foundation of knowledge, but the complexity of problems faced by the world in recent times requires problem-defining and solving perspectives that cross disciplinary and cultural boundaries. Secondly, she points out that an internationalised curriculum or internationalising the curriculum would be moving away from dominant and emerging paradigms which most often dominate most curriculum development discusses. A break away from this dominance and imagining new ways of thinking which move beyond the local context to inculcate perspectives which had otherwise been delegitimized is key to internationalising the curriculum. Thirdly, requirements of professional practice and citizenship are important considerations when decisions are on what to include or not include in the curriculum, especially if such programs need international or external accreditation. Since university education is not just about training professionals to meet the demands of the world, the moral responsibilities that come with both local and international citizenship are key considerations when internationalising curriculum. Fourthly, assessment of student learning needs to move beyond traditional assessment of learning in the classroom to how students have understood and adapted international and intercultural learning goals. Fifth, systematic development across the program for all students is vital for the internationalisation of the curriculum. To ensure systematic development for all students, there must be collaboration and careful planning amongst colleagues within the program. The development of skills such as language capability and intercultural competence may need to be embedded in a number of courses at different levels. Since different students enter the program with different capabilities, a range of strategies to assist all students to achieve desired learning outcomes by the end of the program would be needed. Six, the institutional context 
must be developed in ways that both the formal and informal curriculum work together to produce the desired outcome in students. Highlighting one without the other would weaken the internationalisation process since local students need to learn the international perspective and international students need to learn the local perspective. The institutional context if well-developed can effectively drive this. Seven, the local context is vital if students are to be ethical and responsible local citizens who appreciate the connections between the local, the national and the global. The local context includes social, cultural, political and economic conditions. Highlighting the local context would give all and sundry the opportunity to develop systematically. Eight, the national and regional context is as important as the local context especially when it concerns government policies that affect student mobility and would be well inculcated in the curriculum and determines what level the curriculum is internationalised. Lastly, the global context is a complex one with unequal power dynamics like globalisation which is being experienced as discriminatory and oppressive in some places and beneficial and liberating in others. To this end, the global perspective must be understood for what it is if students are to go forth and function effectively at the global stage. Globalisation has drastically contributed to the increasing gap between the rich and the poor of the world, and the exploitation of the global South by the 'North'. This domination which is also intellectual in nature needs to be addressed by finding alternative educational models to defining what is knowledge, who will apply it and to what ends.

van der Wende (1996) and Dunne (2011) offer an alternative framework for curriculum internationalisation with a nine-point agenda. The first sees an internationalised curriculum as having an international subject. This means the curriculum goes beyond a single course to the entire program. The second sees the internationalised curricula as curricula in which the traditional/original subject area is broadened by an internationally comparative approach. In other words, the traditional confines of the discipline are expanded to offer a unique international perspective. Thirdly, an internationalised curricula is one that prepares students for defined international professions. To this end, it doesn't simply seek to train students for the local job market, but for the international stage. The fourth, sees the internationalised curricula as curricula in foreign languages or linguistics which explicitly address cross-communication issues and provide training in intercultural skills. To this end, language needs of all students are met and training on intercultural skills are provided to give student the best experience of the curriculum. The fifth, sees internationalised curricula as one with interdisciplinary programmes such as regional and area studies, covering more than one country. That means students don't simply hear of cultures but get to experience first-hand across a broad spectrum or nations as well as across disciplines in different nations giving them the best experiences. The sixth, sees the internationalised curricula as that which would lead to internationally recognised professional qualifications. If a decree can be recognised across a broad spectrum of nations, then the curriculum can be said to be internationalised. The seventh, sees an internationalised curriculum as that which leads to joint or double degrees. To this end, programs which leads to combined majors, joint or double degrees are internationalised. The eight sees curriculum internationalisation as curricula in which compulsory parts are offered at institution(s) abroad, taught by local lecturers. This means students get different lecturers teaching them different aspects of the course or different courses in the program in different international settings. This ensures that students get a true international experience. Lastly, an internationalised curriculum can be seen as that in which the content is especially designed for foreign students. These nine key constructs offer a comprehensive way of identifying an internationalised curriculum.

However, just like in any context, it is difficult applying this in its entirety in every setting especially when the phenomenon of curriculum internationalisation is driven through student engagement. For this purpose, a six-point framework is built or adapted from Leask (2015), van der Wende (1996) and Dunne (2011) to ensure that an internationalised curriculum driven by student engagement would benefit all by improving student experience. The first strand of this curriculum internationalisation framework centres on cross-border perspectives. For a curriculum to be truly international, there is a need for both local and international dimensions to be inculcated within the curriculum. The cross-border perspectives in terms of pedagogy, paradigms, ways of knowing, understandings of the knower, knowledge construction and consumption processes would make sure that graduates are ready not only for the society where they are studying but can be fully functional at a global stage. The second strand of this framework looks at multidisciplinary or interdisciplinary content. Disciplinary content is limited especially when internationalisation is concerned. Most often, most disciplines might be context bound but when content is drawn from a multiplicity of disciplines, it ensures the inculcation of content which brings variety. For example, taking a course in accounting, international relations, political science, media, film, history and literature in a particular program would ensure that the student is well verse not only contextually but with content and provides international dimension to the curriculum thereby bringing about the internationalisation of the curriculum. The third strand of this framework focuses on the local context. For every curriculum to be effective, it requires a strong focus on the local context. The local context in this case encompasses the institutional in particular and the nation in general. Students both local and international need to understand the context wherein they are study for the 
content they are studying to be make practical sense. The national context makes sure that the student can fully function in the society having gain practical knowledge of both the institutional and national context. The fourth strand of this framework focuses on the international context. You cannot internationalise the curriculum without building within it knowledge or perspectives from the international context. It is not enough to know about the international context but it is vital to understand it and how it shapes the local context and vice versa. Knowing how globalisation or global institutions like the World Bank and IMF shape the happenings in the world be it education or trade amongst other things is vital in succeeding in the international sphere. Ensuring an understanding of the international context in the curriculum is ensuring that the curriculum is internationalised. The fifth strand of the framework focuses on the systematic development of students. The curriculum must be structured in ways that both local and internationals students can develop their skills systematically. This is vital because most local students might edge international ones when dealing with the local context, and international students might edge local ones when it comes to the international context. By structuring the curriculum to ensure that student development is harmonious is critical to internationalising the curriculum and ensure that all students get the best educational experience. The sixth and last strand of the framework deal with a tentative informal curriculum. Education goes beyond what happens in the classroom to the other nuanced experiences that happen around the institution. Universities must take steps to ensure that there is a cultural exchange amongst local and international students to ensure that knowledge and experiences about things which would otherwise not be communicated in a classroom can be transmitted. Without a tentative informal curriculum, many students would miss out on valuable experiences which make for responsible citizenship and good judgement in life. By doing this, the institution would be creating room for deterritorialising.

\section{Deterritorialisation}

Dovey, Rao, and Pafka (2018) argue that deterritorialisation can be understood as the loss of territory. Knowledge does not stay in one place, but floats through different spaces and time, be it real or imagined. Since territory offers the notion of boundaries, stability and organization, deterritorialising seeks to promote cross-border, disorder, and fragmenting. Deterritorialisation in education is therefore about moving beyond the territorial confines of education or what it means to education to a new stratosphere where knowledge, ideas and what it means to know is forever moving and is not territory bound but constantly evolving. Barone, Zaro, and de Musacchio (2015, p. 1418) continue that territorial education as seen in most parts of the world "is synonymous with ownership, of closed subjectivity itself, and by being a set of representations that follows on a series of stereotypical, dogmatic behaviours perpetuated for centuries. Deterritorialising education offers a gate way to a new understanding of education in the global world and how student experiences can be altered to ensure the best educational engagement.

Appadurai (1990) and Hernàndez (2006) add that deterritorialisation is a cultural phenomenon which gained grounds in the era of mediatisation, migration, and commodification. It seeks to ensure that people work towards closer involvement with the world lessen the gap with one another. This distancing of education from the locality, is intensified when people are able to expand and alter their imagination through the mediatisation or scaffolding, making education one with familiar or universal material. Deterritorialisation creates new avenues for education and offers students the opportunity to study across border and yet still feel at home.

Stefanova (2018) continue that the deterritorialising experience implies opening up to the world and amplifying cultural horizons through diverse educational activities. This means that deterritorialising transforms the relation between the places where we live and our cultural activities, experiences and identities. Barone et al. (2015) and Dovey et al. (2018) further argued that paradoxically, deterritorialisation also includes reterritorialized manifestations, which are understood as certain relative, partial territorial relocalisations of old and new symbolic productions. This in education is vital especially when studying for degree purposes. Reterritorialisation becomes the configuration of the degree program regardless of the approach the configuration takes. Giddens (2013) adds that deterritorialisation speaks of the loss of the natural relation between culture and the social and geographic territories, and describes a deep transformation of the link between our everyday cultural experiences and our configuration as preferably local beings.

Deterritorialisation is fostered by the construction of a plane of immanence. Deleuze (2001) argues that the plane of immanence is about existing or remaining. The plane of immanence is a land of opportunities, open to all possibilities. This plane is "a pure immanence, an unqualified immersion or embeddedness, an immanence which denies transcendence as a real distinction. Pure immanence is thus often referred to as a pure plane, an infinite field or smooth space without substantial or constitutive division (Deleuze, 2001, p. 40). The plane of immanence is only pure when immanence is no longer immanence to anything other than itself that we can speak of a plane of immanence. Deterritorialisation offers a platform for the internationalisation of the curriculum. It provides a plain field for engaging on curriculum matters which need careful interrogation in an open field. The framework for curriculum internationalisation requires an 
open field for engagement because of the numerous concessions that are required to make it a truly international curriculum.

\section{Deterritorialising Curriculum Internationalisation through Student Engagement}

This part of the paper engages the four perspectives of student engagement (behavioural, psychological, socio-cultural and holistic perspective) alongside the six points curriculum internationalisation framework (cross-border perspectives, multi-disciplinary or interdisciplinary content, local context, international context, systematic student development, tentative informal curricula) on the platform of deterritorialisation. Internationalising the curriculum is first about engaging cross-border perspectives. It is the pathway for engaging perspectives on a variety of fronts and building into curriculum pedagogy, paradigms, ways of knowing, understandings of the knower, knowledge construction and consumption processes which are beyond the borders, particularly national borders. For this to be effective, students' needs need to be taken into consideration to ensure that the curriculum being developed gives them the best academic experience (Coates, 2010). Engaging students is therefore vital to understanding their needs and seeking curriculum material which would meet their needs. The behavioural perspective of student engagement is vital for cross-border engagements. The behavioural perspective of student engagement demands an interaction between students and the institution. This interaction would reveal the needs of students to staffs of the institution or those whom students are interacting with. The platform or purpose of this interaction however must be linked to personality and behavioural needs which the curriculum needs to address to produce a better citizenry. Behavioural patterns are deterritorialised and kept in constant existence. Since curriculum is the sum total of all educational experiences students have (Fomunyam, 2014), it seeks to build and mold the student into a specific kind of individual as evidence in the ideological considerations and theoretical underpinnings grounded in the curriculum. Engaging students on behavioural perspectives ensures that the institution understand the behavioural foundations of both local and international students and tailor a curriculum that addresses this need from a cross-border perspective such that where ever this students are functioning, they would have the skills and behavioural aptitude to blend. Furthermore, the socio-cultural perspective of engagement focuses on institutional culture and wider contextual issues. That is the conditioning and enabling factors within the institution that makes for engagement. The institutional culture needs to be understood from both the students and institutions perspective to ensure that solutions from beyond the border as well as within the border can be fashioned to ensure that the culture facilitates the process of learning. By ensuring cultural contact through engagement and building the same within the curriculum, a plane of immanence would be created for a truly international curriculum which engages perspectives like pedagogy, paradigms, ways of knowing, knowledge construction processes both cultural and behavioural in nature using a cross-border perspective. Stefanova (2018) concurs with this when he argues that the plan of immanence is a land of opportunities, open to all possibilities. The plane of engagement is therefore botherless and perspectives are traded back and forth to ensure that all students needs are addressed.

The curriculum is predominantly about the content and for such to be truly international, there is need to deterritorialise the content thereby creating a multidisciplinary program or an interdisciplinary curriculum content which speaks to a wide variety of fields and addresses a wide variety of needs. Fomunyam (2014) argues that content is the bedrock of education and giving students a wider scope in content would result in improved or better learning experiences. Ensuring that the content of courses come from a wide variety of disciplines and this content is delivered or tinged with cross-border perspectives is a pathway to internationalising the curriculum. Haigh (2002, p. 52) argues that "beyond the provision of equal opportunities for learning and advancement, the ambition of most internationalised curricula is to create graduates who are capable of engaging in a culture of communication and work that is becoming increasingly global”. The global work space is increasingly becoming an interdisciplinary one with every professional needing knowledge of his or her field as well as knowledge of a wide variety of fields like information and communication technology, globalisation and its constituent constructs, leadership amongst others. Only a multidisciplinary curriculum can provide equably for the learning ambitions of all students, irrespective of their national, ethnic, cultural, social class/caste or gender identities (Haigh, 2002). Since its (international curriculum) values social inclusion, cultural pluralism and 'world citizenship' ahead of partisan links with any smaller geographical, cultural or social unit, only an interdisciplinary approach to curriculum development can deliver at such levels. Kahu (2013) concurs with this in his argument on the psychological perspective of student engagement. He opines that students make huge psychological investments towards learning, understanding, or mastering the knowledge skills or crafts. This mastery is honed in from a variety of disciplines to produce self-regulation through deep learning strategies.

Appleton, Christenson, Kim, and Reschly (2006) add that psychological engagement further deals with the relevance of curricula to future endeavours, value of learning, personal goals, feelings of identification or 
belonging, and relationships with staff and peers. This can only be gotten from a multidisciplinary curriculum which ensures that students get everything they need from a wide variety of disciplines. This would also make the discipline deterritorial and give students the opportunity for different levels of culture contact which makes for value in learning, empower to achieve personal goals and ultimately provide a sense of belonging. Appleton et al. (2006) further add that a sense of belonging in the institution, ownership of the curriculum and identification with the education process become by products of student engagement and this can only be possible if the curriculum is deterritorialised and internationalised by making it multidisciplinary. A multidisciplinary curriculum would bring multidisciplinary support which empowers students both national and international to maximise their potentials within the education system. Since student engagement is also about improving student performance and experience, curriculum internationalisation through multidisciplinarity would ensure that students performance improve as they get to own the curriculum and construct learning experiences in a wide variety of fields and in a wide variety of ways. Zepke (2014) concludes that students need both control and autonomy in their learning experience and interdisciplinarity is one way of ensuring that. International students for example can shuffle between disciplines to take courses which would give them a better understanding of the context they are in, and local students can do the same to get a better understanding of the international stratosphere. This multidisciplinary context would encourage students to have a critical view of their learning (since they can compare experiences from across disciplines) and be able to disengage without being characterised as alienated. Curriculum internationalisation is possible on the platform of deterritorialisation through student engagement.

Local context as the third agenda on the curriculum internationalisation framework is poised towards building a locally responsive citizenry or students who are ethically responsible and appreciate the connections between the local, the national and the global. Brinegar and Bishop (2011) argue that context is key to curriculum development and delivery especially because it informs the kind of resources available, what kind of teaching approaches to use, the student make up within the university and also include social, cultural, political and economic conditions. Fomunyam (2017) adds to this when he argues that without a practical consideration and understanding of context, the curriculum can never be effective in delivering the desired outcome. Internationalising the curriculum therefore is also about highlighting the local context especially because this is the point of contact for education and contributes to the overall educational experience. In cases where the program takes place on multiple campuses across different nations, this different context constitutes the local context which must be considered in internationalising. Part of the educational experience for international and local students (in cases where they are studying in areas within the nation yet unknown to them) is getting firsthand understanding of how things happen in different context. It is on the basis of this context that mutual engagement is stimulated, and students become initiated into the context. The holistic perspective of student engagement sees education as much more than acquiring knowledge to encompass the perceptions, expectations, and experience of being a student and the construction of being a student (Kahu, 2013). This means that the curriculum should carry with it the fortitude of becoming and not qualifications. The experience and participation in the local context would build the individual and equip him or her with social and cultural capital which they otherwise did not possess which makes for becoming. Zepke (2014, p. 704) argues that "the effects of specific cultural, power and other contextual differences seem imperfectly recognised in student engagement...and suggest that quality in engagement requires institutional cultures that cater for diversity, and not be blind to cultural and other differences”. Recognising these differences or diversity in the institution and providing the context or platform for engagement empower students to tab into what otherwise is seen as useless. She continues that "not recognising contextual and personal diversity has shown that students who arrive in a tertiary institution with cultural capital or 'familial habitus' congruent with the existing institutional habitus, are likely to be 'fish in water' and succeed, while students who think their cultural and personal practices are incongruent, they are likely to feel like 'fish out of water' and not engage" (Zepke, 2014, p. 704). The impact of ethnicity, age, gender, socio-economic status, lifestyle and beliefs in education cannot be neglected and local context open the door for the recognition of all these. Tapping into the local context becomes a way of reterritorialising and highlighting the importance context and the process of becoming in the context (Deleuze, 2001). This is especially vital because knowledge is never created in a vacuum and educational experiences are shaped by the context. The context therefore becomes part of the experiences every student returns with. Internationalising the curriculum is impossible without and engagement with the local context.

The international context on the other hand is poised towards moving towards the globe. It seeks to propound knowledge or perspectives that are tabernacled on a variety of context. Fomunyam (2014) makes a case for this when he argues that curriculum and curriculum theory development from a thousand contexts (a combination of the local and the international or multiple context in the international landscape) enhances student experience and makes for better schooling. With the world increasingly becoming a global village and upward and downward migration becoming the other of the day, knowing and understanding the global landscape of a particular field or fields as the case might be and the factors that shape such 
landscape is crucial to finding once place in the global world. Deterritorialisation is all about opening up the barriers for the free flow of knowledge, labour and everything useful in the global context as well as the creation of the plan of immanence for critical global engagements. Knowing how globalisation or global institutions like the World Bank and IMF shape the happenings in the world be it education or trade amongst other things is vital in succeeding in the international sphere. Ensuring an understanding of the international context in the curriculum is ensuring that the curriculum is internationalised. Zepke (2014) argue that in this era of marketisation in the higher education landscape, universities are increasingly being forced or made to train students who are global in their perspective and can fit in the increasingly changing world. Students be it local or international, need an international bearing to fully fit in the global world. Altbach and de Wit (2018) argue that with the success of right-wing nationalist and populist forces in many European countries and part of North America, the higher education community is increasingly witnessing low migration rates, increased problems obtaining visas, an unwelcoming atmosphere for foreigners and other issues which are causing a decline in international student numbers in the United Kingdom and the United States. In response to these challenges therefore students would most definitely want the best academic experience, one which would empower them to function globally especially with Trump presidency increasingly stressing the need for skilled and skilled migration only into the united states.

The international landscape according to Larner and Walters (2004) is the process of across-boundaries flow and it has profound influence on politics, economics, and culture from every nation can never be denied. People are increasingly realising that their lives are mutually implicated in the distant shore and interdependence between nations and communities. The original divide in the world's territories have lost some authority, or is becoming increasing deterritorialisation. The increasing collaboration in the global south especially in the higher education arena and the increasing impact of international collaborations, the need for graduates who are international in nature cannot be over emphasised. Having the curriculum take into consideration practically the international context would be a practical way of internationalising it and making sure students are not only aware of the international context but can function in it. Kahu (2013) argues that the behavioural perspective of engagement approach does incorporate students' thinking processes as well as behaviour, and how this can be enacted in the global space becomes of paramount concern to the curriculum internationalisation process. Understanding how to think and act in the global sphere can be pioneer through curriculum convergence and divergence. Buy having students engage lived experiences through convergence and divergence, the curriculum would be ensuring that the international context is understood and appreciated (Deng, Gopinathan, \& Lee, 2013). They add that this would also ensure that students understand behaviour patterns in the international landscape as well as understand the thinking patterns and processes in a various context.

Systematic student development is the last but one frame for curriculum internationalisation considered in this paper. Thomas (2012) argues that it has become increasingly clear in the higher education sector that success means helping all students improve their educational experience. This means that the university has a responsibility not to one but to all its students regardless of their background or context. The curriculum must therefore ensure systematic development for all students as a way of internationalising. Hernàndez (2006, p. 93) argues that a "deterritorialised context, everyday globalization experiences makes it increasingly difficult to maintain a stable sense of local cultural identity, including national identity, as our daily life entwines itself more and more with influences and experiences of remote origin". This offers the higher education curriculum a unique opportunity to deal with a student at the same level. With the elimination or near elimination of local and global identity students can engage it behaviourally, psychologically, socio-culturally or holistically to ensure that development for everyone is systematic. This means tailoring the curriculum in ways that all students' development are systematic. While systematic development for all students can be very challenging owing to the different cognitive levels possessed by the students, the curriculum must recognise this and tap into these differences to ensure that some forms of systematic development and progress happen for the students. Leask (2015) argues that systematic development across the program for all students is vital of internationalisation of the curriculum. And for this to happen there must be collaboration and careful planning amongst colleagues within the program. The development of skills such as language capability and intercultural competence may need to be embedded in a number of courses at different levels. Since different students enter the program with different capabilities, a range of strategies to assist all students to achieve desired learning outcomes by the end of the program would be needed. The multidisciplinary component of curriculum internationalisation becomes increasingly useful as students are made to upgrade their competences in areas where they are lacking. Students engaging amongst themselves can as well ensure their systematic development through diverse practical exchanges.

Ensuring the practicality of these and seeing how the holistic perspective works for all students require continues assessment of their performance to ensure that the curriculum is kept in motion, and constantly re-conceptualised to ensure that where students are lacking 
behind relevant disciplines can step in to assist. Stefanova (2018) argues that deterritorialisation intensified by the process of mediatisation becomes of special importance to the alterations experienced by the experiences of students and this constitutes one of the basic factors to understand the process of development. Within the confines of deterritorialisation, the process of a mediatisation becomes increasingly important as students become intervening authorities in their own studies thereby mediating the place of the academic staff where he or she is competent. Students therefore become a holistic entity in their differences or the notion of unity in diversity becomes particular important as the one taps on the other ensuring that everyone is carried along. Curriculum internationalisation in this sense is ensuring student development by creating avenues for development, counter development conceptualisation and reconceptualisation of the curriculum to ensure that everyone is supported to develop systematically and holistically.

Curriculum is as formal as it is informal and how structured both the formal and informal curricula are determine the kind of experiences students end up. In the era of internationalisation a tentative informal curriculum is vital to ensure that students develop soft skills which otherwise might be missing in everyday practical class. Suchman et al. (2004) argue that one of the most consequential and enduring aspects of learning is the formation of a set of personal beliefs, values, and role expectations that guide and inform virtually all subsequent behaviour. They continue that students tend to internalise and perpetuate the patterns of behaviour that surround them-the way they see people treating each other and the way they themselves are treated. The psychological perspective of student engagement is vital for the development and growth of the students. Cottingham et al. (2008) add that the informal curriculum consistently reinforces the values of the formal curriculum, promotes mindfulness on the part of every faculty member, resident, and staff member about the values we exhibit and thereby teach in our everyday interactions. Having a tentative informal curriculum which would determine what kind of activities students would undertake, for how long and how they would go about it so they can develop certain skills and abilities would help improve their educational experience and competences. van der Wende (2000) confirms this by arguing that informal learning can provide new migrants and refugees with important foundation skills to integrate into their new communities, upon which further learning can be built. With the increasing impact of social media and technology informal learning situations can be less costly and more time efficient. van der Wende (2000) adds that the informal curriculum is as important as the formal curriculum in improving interactions between home and international students. Learning informally becomes more personal and less intimidating for some people as more experts in the field or area of focus are more willing to share their knowledge with others this way.

Leask (2009) argues that the informal curriculum has been used to increase and improve student experience and engagement. She points out that developing learning guides which provides basic inside into the languages spoken by all parties concerned, the assignment of buddies or mentors (local students) for visiting international students, online peer-mentoring systems or programs where students can communicate via e-mail and in online discussion groups and negotiated face-to face contact at mutually convenient times following the international students arrival on campus, conversation groups for international students facilitated by language and learning experts, advisers to assist international students to develop their social language skills throughout the academic year, regular get-togethers on each campus for international students to meet informally and discuss issues, raise questions, and get to know each other better, cross-cultural lunches for international and domestic students facilitated by a trained counsellor amongst others are examples of informal curricula activities which have been used to improve students education experience. When domestic students interact with international students, a window is opened for mutual benefits as they both draw from such experiences. Leask (2009, pp. 217-218) concludes that "using the informal curriculum to improve interaction between home and international students is a complex matter that, as a site of intercultural communication, involves students and staff moving into a third place.....and it is important to focus and structure interventions so as to encourage and support the engagement of home students in their interactions with international students, as well as encouraging and supporting international students to interact with home students". Also, well-tentative or well-planned informal curriculum aimed at enhancing curriculum internationalisation must recognise the relationship between the formal and informal curriculum and the importance of both in the internationalisation process. Ensuring the presence of a tentative informal curricula in the internationalisation of the curriculum is paramount in ensuring that students get the best experience and encounters of both home and abroad.

\section{Conclusions}

Curriculum internationalisation in the higher education sector is a complex process with a complex understanding and curriculum developers need to take into consideration a number of issues in ensuring that the internationalisation process is successful. In this light, it suffices to begin with a deterritorialisation of the field and create a gateway for exchanges and conceptualisations that are not specifically bound to context, space or time but to the experience. To this end, this paper concludes with the following thoughts. Firstly, curriculum internationalisation should be 
contextual in nature. That is, it must be tailored to address the specific needs of the students it is meant for. There would be no universally applicable internationalised curriculum because student needs and abilities are different. Secondly, deterritorialisation of the institution and the curriculum internationalisation process and the curriculum itself are key to successfully internationalising the curriculum and giving students the best educational experience. Deterritorialisation brings within it the possibilities for reterritorialisation upon completion of the internationalisation process thereby ensuring that students are experts in their own right upon completion of their study both at the national and the international landscape. Thirdly, for the curriculum internationalisation process to be successful, there is a need for a practical framework which takes into consideration the needs of the students, the course of study, the institutional context and culture, the nature of the program and how the program would be offered in ensuring that the best experience is provided. The framework must be such that would provide the opportunity for the reconceptualisation of the curriculum at every point in time as well as the review of the curriculum in process to ensure that students are provided with the best experience. Fourthly, student engagement is critical in the internationalisation process and for the success of curriculum internationalisation itself. Engaging students or taking the different dimensions of student engagement into consideration in the curriculum internationalisation process is paramount especially because internationalising the curriculum is all about improving student experience and ensuring that graduates are effective and proficient. Creating avenues for student engagement in the internationalisation process, would ensure that when the curriculum is being enacted, practical engagement takes place.

Deterritorialising curriculum internationalisation is therefore paramount and critical especially because this can be done on the platform of student engagement. This process would give students a voice in the conceptualisation and reconceptualisation of their curriculum and the knowledge construction process as they begin to express agency in the higher education landscape. Since student engagement is about better or improved educational experiences, deterritorialising curriculum internationalisation becomes a must to level the playing field and makes sure that all stake holders are taken into consideration and the best experience for teaching and learning is guaranteed.

\section{REFERENCES}

[1] Altbach, P., \& de Wit, H. (2018). The challenge to higher education internationalisation. University World News. Retrieved fromhttp://www.universityworldnews.com/article.php?stor $\mathrm{y}=20180220091648602$

[2] Appadurai, A. (1990). Disjuncture and difference in the global cultural economy. Theory, culture \& society, 7(2-3), 295-310.

[3] Appleton, J. J., Christenson, S. L., Kim, D., \& Reschly, A. L. (2006). Measuring cognitive and psychological engagement: Validation of the Student Engagement Instrument. Journal of School Psychology, 44(5), 427-445.

[4] Axelson, R. D., \& Flick, A. (2010). Defining Student Engagement. Change: The Magazine of Higher Learning, 43(1), 38-43.

[5] Baron, P., \& Corbin, L. (2012). Student engagement: rhetoric and reality. Higher Education Research \& Development, 31(6), 759-772.

[6] Barone, D. A. C., Zaro, M. A., \& de Musacchio, C. (2015). Delocalization and Spatialization of the Classroom: Deterritorialization in Education. American Journal of Educational Research, 3(11), 1417-1428.

[7] Brinegar, K., \& Bishop, P. A. (2011). Student learning and engagement in the context of curriculum integration. Middle Grades Research Journal, 6(4), 207-223.

[8] Coates, H. (2010). Development of the Australasian survey of student engagement (AUSSE). Higher Education, 60(1), $1-17$.

[9] Cottingham, A. H., Suchman, A. L., Litzelman, D. K., Frankel, R. M., Mossbarger, D. L., Williamson, P. R., . . . Inui, T. S. (2008). Enhancing the informal curriculum of a medical school: a case study in organizational culture change. Journal of General Internal Medicine, 23(6), 715-722.

[10] Deleuze, G. (2001). Pure immanence. New York: Zone

[11] Deng, Z., Gopinathan, S., \& Lee, C. K.-E. (2013). The Singapore Curriculum: Convergence, Divergence, Issues and Challenges. In Z. Deng, S. Gopinathan, \& C. K.-E. Lee (Eds.), Globalization and the Singapore Curriculum: From Policy to Classroom (pp. 263-275). Singapore: Springer

[12] Dovey, K., Rao, F., \& Pafka, E. (2018). Agglomeration and assemblage: Deterritorialising urban theory. Urban Studies, 55(2), 263-273.

[13] Dunne, C. (2011). Developing an intercultural curriculum within the context of the internationalisation of higher education: terminology, typologies and power. Higher Education Research \& Development, 30(5), 609-622.

[14] Fomunyam, K. G. (2014). Curriculum theorizing and individualism: An exploration of the curriculum's relation to the social, personal and political dimensions of schooling.

[15] Fomunyam, K. G. (2017). Decolonising the Engineering curriculum in a South African University of Technology. International Journal of Applied Engineering Research, 12(17), 6797-6805.

[16] Giddens, A. (2013). The consequences of modernity. Cambridge: John Wiley \& Sons.

[17] Gunuc, S., \& Kuzu, A. (2015). Student engagement scale: 
development, reliability and validity. Assessment \& Evaluation in Higher Education, 40(4), 587-610.

[18] Haigh, M. J. (2002). Internationalisation of the Curriculum: Designing inclusive education for a small world. Journal of Geography in Higher Education, 26(1), 49-66.

[19] Hernàndez, M. (2006). The deterritorialization of cultural heritage in a globalized modernity. notes \& comments, 92-107.

[20] Kahu, E. R. (2013). Framing student engagement in higher education. Studies in Higher Education, 38(5), 758-773.

[21] Larner, W., \& Walters, W. (2004). Globalization as governmentality. Alternatives, 29(5), 495-514.

[22] Leask, B. (2009). Using formal and informal curricula to improve interactions between home and international students. Journal of studies in international education, 13(2), 205-221.

[23] Leask, B. (2015). Internationalizing the curriculum. London: Routledge.

[24] Leask, B., \& Bridge, C. (2013). Comparing internationalisation of the curriculum in action across disciplines: theoretical and practical perspectives. Compare: A Journal of Comparative and International Education, 43(1), 79-101.

[25] Stefanova, B. M. (2018). The Deterritorialization of European Regionalism: Global Perspectives The European Union and Europe's New Regionalism (pp. 159-201): Springer.

[26] Suchman, A. L., Williamson, P. R., Litzelman, D. K., Frankel, R. M., Mossbarger, D. L., \& Inui, T. S. (2004). Toward an Informal Curriculum that Teaches Professionalism: Transforming the Social Environment of a Medical School. Journal of General Internal Medicine, 19(2), 501-504.

[27] Thomas, E. (2012). Building student engagement and belonging in Higher Education at a time of change: final report from the What Works? Student Retention \& Success programme. London: Higher Education Academy.

[28] van der Wende, M. (1996). Internationalizing the curriculum in higher education: Report on a OECD/CERI study. Tertiary Education and Management, 2(2), 186-195.

[29] van der Wende, M. (2000). Internationalising the curriculum: New perspectives and challenges in: Hudson, B. and $M$. Todd (eds.), Internationalizing the curriculum in higher education. Reflecting on practice: Sheffield Hallam University Press.

[30] Vuori, J. (2014). Student engagement: buzzword of fuzzword? Journal of Higher Education Policy and Management, 36(5), 509-519.

[31] Zepke, N. (2014). Student engagement research in higher education: questioning an academic orthodoxy. Teaching in Higher Education, 19(6), 697-708. 